\title{
Plunder without Danger: Avoiding Responsibility in Rural Works Administration in Bangladesh ${ }^{1}$
}

\author{
Geoffrey D. Wood
}

\section{The Problem}

In a formal sense, an administrative system must meet two requirements, which constitute a measure of its competence. It must deliver the goods actually ordered by the political system, and it must do so in a cost effective way. The problem of incompetence then takes two forms. Monopolistic positions can allow administrators to expand costs to the outer limits of any potential budgetary allocation without improving services. Secondly, such positions enable them to alter the way in which the programme is implemented, and thus fail to achieve the goals actually intended. However, this formulation of the problem relies heavily upon a sequential image of the policy process, consisting of discrete stages of goal setting, appraisal, implementation, evaluation, etc. in which different sets of actors are involved. This is rarely the case anywhere, though the image sustains an important illusion of rationality [Wood 1986]. In countries like Bangladesh, a particular combination of circumstances complicates the picture still further. The nature of the regime, with weak structures of public accountability, strengthens internally the monopolistic position of the bureaucracy as a whole, and senior officials within it. At the same time, the maintenance of such monopoly depends crucially upon its dominant ability to manipulate external aid flows which represent 80 per cent of the country's development budget. In this process, its own interests can be challenged by the sets of ideologies which underpin such aid: whether the privatisation initiatives endorsed by the World Bank and USAID (the major sources of aid to Bangladesh) or the 'target-group' approaches of the Scandinavian and other small bilateral donors in which the 'landless' and 'women' feature prominently. Bangladesh, then, represents an extreme case of a situation found quite commonly in Third World countries, when external aid agencies sponsor projects designed to meet the political criteria and standards of bureaucratic provision determined in their own countries, rather than those of the host countries.

\footnotetext{
This discussion is based on sporadic fieldwork as a consultant to the programme and as a participant in the evaluation of it. This fieldwork has consisted of: visits to project sites; interviews and discussion with siteworkers, field officers, government and aid officials, staff of NGOs which were participating in the programme; and extensive reading of the documentation provided by the programme's own monitoring activity.
}

This article will explore a situation in which 'targetgroup' approaches are attempted through extant local government institutions which continue to function within national and local patron-client networks, and which ensure that it is the needs of the local political and economic elite which come to be maximised rather than those of the 'target group' originally intended by those who initiated the programme [see also Wood 1983 and 1985b]. In this process, administrative structures reveal their real rather than their formal content, i.e. not simply as instruments of the domestic political system or external agency, but as reflections of local political and economic power structures. The interests which emerge in these structures derive from the opportunities offered by administrative office in a society where other avenues of accumulation are limited. Where these interests are unsympathetic to the goals of the external agencies (whether privatisation or 'target-group'), a large gap will emerge between objectives and achievement.

This gap can be explained, therefore, by understanding the administration of the programme as a set of opportunities for state officials to service political and economic objectives in a manner which reorients activities to serve local rather than externally set goals. By doing this we can begin to develop a more complex view of the sources of administrative competence than one which confines itself to the inner structure of the bureaucratic system alone, and which therefore approaches the problem of reform in the same way. By looking at administration in this way, we can then attempt to identify the real constraints which affect the ability of well-intentioned liberal donors to deliver benefits to politically and economically disadvantaged groups, and thus enable them to set more realistic objectives and to pay more attention to the institutional framework through which they make their interventions.

In this article I will look in particular at a public works programme in rural Bangladesh. Among the many ways of describing Bangladesh, the salient features for the purpose of this analysis are: a deltaic region with regular flooding, wandering rivers, rich alluvium siltation; particular areas which are prone to extreme flooding; minor variations in the elevation of plots within the same locality are significant in determining farming practices; the major social transformation of the last 30 years has consisted of a rapid rise in the 
proportion of rural landless to the point where they now constitute approximately 50 per cent of the rural population; the formation over the last decade of indigenous non-governmental organisations (NGOs) working with the rural poor in consciousness-raising and income-generation programmes; approximately 80 per cent of the development budget funded out of foreign aid; and evidence of considerable bureaucratic corruption and misappropriation stimulated by a virtual government monopoly over the use of external funds.

In 1981 Swedish, Norwegian and Danish aid was used to set up an Intensive Rural Works Programme (IWRP) in Bangladesh which had explicit long-term 'target group' objectives for the rural poor. This involved the building of rural infrastructure (roads, embankments, canals, bridges, drains, sluices and culverts) to improve rural productivity and economic security, but to do so using labour intensive methods in which wages would represent 70 per cent of total investment cost and in which women from landless and marginal peasant households would be explicitly included. The programme also wished to extend rights to these workers beyond short-term wage employment through access to related production activities and, to ensure this, to involve site workers in the planning and implementation of the schemes.

\section{The Institutional Framework}

The programme was administered through the Ministry of Local Government and its Works Programme wing, which was later renamed the Local Government Engineering Bureau (LGEB). At the local level this coincided with a major local government reform in which more authority and resources were decentralised to Upazilas, or local government sub-districts. These structures involved Upazila Nirbahi Officers (UNOs: governmental officers deployed by the Ministry) and elected chairmen. These have responsibility for the Upazila Planning Committees and for nominating the members of the Project Committees set up to manage the IRWP schemes.

Within these structures engineers exerted considerable influence at all levels, and tended to justify decisions involving 'hard' expertise on physical aspects to the programme on purely technical grounds. Yet the exercise of these technical judgements invariably involved choices which had significant social and distributional consequences by producing new land, enhancing the quality of old land, altering the pattern of labour demand and increasing access to internal and external markets. These choices represented sets of opportunities, within authoritative local government structures, where political alliances could be struck or sustained between local state officials and rural patrons in which they were able to reproduce and extend their respective interests, even within the context of a technical engineering programme designed by well-intentioned outsiders for (rather than with) the rural poor.

But with the employment generation objectives embedded in the original programme, we cannot explain the outcome solely with reference to the public structures involved, since these had to interact with private sector networks in order to produce the labour required for the schemes. Labour was recruited through sardar and patronage networks which were connected to the local administration; workers were dependent for credit and other needs on the local patrons who were also managing the rural works schemes; in the rural underemployment conditions of Bangladesh workers are also divided among themselves, competing for scarce employment opportunities and thus vulnerable to wage exploitation. Under such conditions, they are unlikely to pursue their official rights in the programme with any degree of militancy. Different labour gangs and individuals only participated sporadically in sitework, thereby undermining any prospect of unity. Thus the members of the 'target group', originally chosen as the prime beneficiary of the project, were economically and socially dependent on the very classes of rural patrons who exerted direct control over the recruitment of labour. Yet the mobilisation of labour was a central feature of the programme, designed to serve the interests of rural landless and near-landless workers, rather than those of the rich and powerful elements in the community.

\section{The Results}

It is therefore not surprising that in the event, the redistributive objectives were not actually achieved. The eventual wage component as a proportion of the investment budget was between 16 and 27 per cent, assuming one million man-days of work and wagerates of Tk. 15-25 per day. The investment budget represented only 58.8 per cent of the total budget, so that no more than 10-15 per cent of total project funds actually went to site workers in the form of wages. Further, given the seasonal pattern of labour demand in the region, it was essential that the labour demand be created at the right time in order to reduce seasonal fluctuation and the reliance of workers on credit from local moneylenders and employers. Yet in the event, most of the schemes were started too late, so that the additional employment did not maximise the wider effects upon the structural position of the workers in the local political economy.

The remainder was absorbed by contractors, staff costs, equipment, training, expatriate technical assistance and misappropriation. In 1984/85, for example, the cost of each workday created was Tk. 160, approximately ten times the average daily 
wage for sitework. It is also clear that these high overheads did not have the effect of guaranteeing that the longer term objective of distributing control over assets to the poor would be met. In addition, the programme's own monitoring exercise established that labour records (an important index of power) were not being properly kept, and as a result workers were being systematically underpaid. Further, those schemes intended to provide women with special opportunities involved very substantial use of male labour, inadequate provision of special amenities included in scheme guidelines, falsification of Muster Rolls and cheating on payments. And these 'irregularities' occurred despite an average of 15 visits per season by field officers, supported by expatriate counterparts, to monitor 'socio-economic' performance.

Implementation of the original flood control, drainage and irrigation canal objectives of the programme have been slow, along with the realisation of linkages to 'target group' interests (including those of small farmers). In principle, opportunities exist from the design stage of these schemes for the landless to be involved directly in irrigation, maintenance, embankment cultivation (or social forestry) and in self contracting for the earthworks. But here a struggle has clearly been taking place even over the more limited objective of identifying areas of small farmer concentration for flood protection through embankments. On the surface, this takes the form of a struggle over the interpretation of data, but this masks underlying political conflicts. Here a group of socioeconomists is responsible for conducting screening surveys to identify the areas predominantly occupied by small farmers where embankment/canal construction should take place. But they have been placed under pressure to 'reconsider' their findings in areas where senior engineer/officials have committed themselves technically to another scheme, often in conjunction with the interests of local political actors.

This initiative to skew the benefits of rural works construction towards the 'target-group' of small farmers threatens both the interests of rich farmers in the area as well as the monopoly of control over earthworks projects by the cadre of engineering officials at local and HQ level. These officials insist that priority should be given to technical rather than socio-economic feasibility studies, and that their technical decisions should not be constrained by any previously established parameters of social objectives. But of course, any particular alignment of embankments gives the adjacent owners a rent free enhancement of the long term productivity of their land, while the land lost to embankments is likely to represent a higher proportion of the fixed productive capital of small farmers than of large ones. In the last analysis, it is the Upazila planning committees which have the final say over scheme design and alignment, and small farmers have far less influence here than rich ones.

The result has been a process of 'negotiation' on these committees to reduce the random nature of plot distribution relative to the embankments, so that more of the small farmers' land and less of the richer farmers' land is deliberately adjacent to the final align ment. This process stimulates a flow of bribes to engineering officials and their 'brokers' among the community. Thus here again the intrusion of a 'market' into a supposedly bureaucratic (in the sense of the 'objective' use of unambiguous data) and technical allocation based on redistributive criteria has marginalised the interests of the poorer farming households.

Further, the excavation and re-excavation of fishponds associated with the construction programme represents an opportunity for the acquisition of longterm assets by the landless which the IWRP programme did wish to ensure. Yet in this and other programmes in Bangladesh, these opportunities have not been realised because of manipulation by local patrons with the connivance of local officials. Funds were used for excavation without honouring the accompanying provision that the earthworkers have long term leasing rights to the ponds. In the IRWP, of 27 re-excavated fishponds in one of the programme's districts, at best three could be superificially described as managed by the 'target group'.

Yet it was clear that even these had been infiltrated and were dominated by the non-landless. This experience is similar to the attempts by the Bangladesh Rural Development Board (BRDB) to mobilise landless groups around fishponds.

\section{Problems of Administrative Responsibility and Accountability}

The IRWP was formulated on the assumption that a given administrative structure inevitably tied into national and local political networks could be turned into a redistributive instrument simply through the external establishment of a set of allocative criteria favourable to the poor and landless, reinforced by a small cadre of expatriate field staff with monitoring functions. This belief stems from what has been a very general set of assumptions about the utility of state as opposed to private institutions as benign vehicles for economic intervention, reinforced by a formalistic understanding of bureaucratic practices and outcomes. The limitations of these assumptions have been explored elsewhere in this collection. Yet the experience outlined above demonstrates very clearly that these assumptions cannot be taken for granted, and that the nature of both the administrative structure and its political context will have a decisive 
impact upon the extent to which the original intentions come to be translated into reality.

The objectives of the IRWP involved using infrastructural investment to create short and long term economic opportunities for the rural poor. Yet such objectives could not be achieved without challenging the local structures of power embedded in the control over land and commerce, while the conditions for such a challenge were very unfavourable. Substantial external aid flows were provided through monopolistic bureaucracies with state patronage decentralised to the Upazila level. Here it interacted with local class relations where the low level of capital formation encourages misappropriation, thus creating an extremely hostile environment within which to work alongside the rural poor.

In this context, it is hardly surprising that the senior officials and engineers in the Ministry were mainly concerned with achieving the physical objectives of the programme. They had a clear interest in institutional expansion, the accompanying development of patronage networks through the recruitment of staff, and the possibility of misappropriation at the 'going rate' from aid-sourced programmes which, as we have seen, meant that the intended beneficiaries received only a negligible share of the assets and incomes, while an excessively large proportion went into 'overheads' rather than actual construction. These transfers and distortions have been made possible through the retreat into a bounded sphere of professional competence in which engineers have exercised a virtual monopoly over certain decisions on technical grounds, and, in the process of asserting the primacy of technique, have attempted to disguise the political implications of the resulting decisions. Indeed, the whole notion of a Planning Committee at the Upazila level contributes towards an image of rational authoritativeness to throw a shadow across reality [Wood 1985a].

But apparently 'technical' choices concerning location, design and materials are nearly always directly political because they rarely have equal or neutral effects upon who gains and who loses both during and after construction. Thus accountability based upon a narrow definition of technical and engineering criteria and sectoral responsibility ceases to be credible. As a defensive ideology, that definition breaks down when the linkages to other sets of relationships can be so strongly observed. In the real world, the failure of the social scientist and the engineer, both as aid and government officials, to communicate their interests (well-intentioned or not) and their institutional constraints (assuming good intentions) to one another has resulted in the exclusion of the landless and marginal farmer households from many potential benefits, alongside proliferation of opportunities for private accumulation by an alliance of rich farmers, contractors, dealers and engineering officials in government service. Friends in senior positions in the Indian Administration Service have always referred to their own Public Works Department (PWD) almost affectionately as 'Plunder Without Danger' - clearly the failure of responsibility in Bangladesh has produced a similar result.

\section{Consequences and Implications}

It soon became evident to the donors that the programme was not achieving its intended objectives. However, this has not led to cancellation but instead to the redefinition of objectives. Certain externalities assisted this process. First, it became government policy to shift the greater part of the most labour intensive of the rural earthworks to the Food for Work Programme (FFWP) which is the main vehicle for administering food aid in the countryside and, despite large-scale misappropriation, provides some employment relief in the lean months of agricultural employment. But it makes no attempts to mobilise siteworkers around their wage rights or to offer longer-term control over the assets created by their own labour. In no sense is it a programme seeking structural change. Secondly, the government has also shifted the administration of road maintenance, which employs siteworkers in localised small-scale patching, to CARE, the US relief organisation which often undertakes contracts for USAID supported programmes. USAID is supporting District road construction in Bangladesh, and CARE has experience of rural works through its management of the FFWP.

At the same time, there had been constant pressure from the government throughout the programme to expand the programme's operations into other areas defined in the original proposal as flood prone. This may be interpreted either as a genuine desire to spread the effects of infrastructural investment, or as a further set of opportunities to service its patronage networks at the local level. Whatever the interpretation, some expansion did occur, thereby weakening any capacity within the programme to supervise both the technical engineering aspects of the work, and any attempts to achieve 'target group' objectives through the vehicle of rural works.

Both of these sets of conditions assisted the process of redefining objectives by default, as it were. However, this was more formally achieved during the period of formal evaluation, which took place at the end of 1985. Prior to the evaluation, the sense of failure among some of the committed expatriates had already prompted an exercise to search on the one hand for institutional alternatives involving NGO support for siteworkers, and on the other for broader strategies of employment generation not confined to the construction of earthworks infrastructure, and not, 
therefore, confined institutionally to the LGEB and the local government/Upazila structures. A draft phase 2 project proposal therefore already existed before the evaluation. The severe criticisms of the evaluation mission unwittingly lent support to two outcomes not intended by this search, amounting simultaneously to redefinition and legitimation. The IRWP was renamed the Rural Employment Sector Programme (RESP) with two components: the Infrastructure Development Programme (IDP) and the Production and Employment Programme (PEP). This is the current programme. The IDP represents about 90 per cent of programme funds, supporting infrastructural schemes (feeder roads, small-scale water schemes), training and institution-building. Although, of course, it employs labour, the primary justification for this component is now the general value of infrastructural development to increasing productivity, security of land and transportation. The idea of rural works as a vehicle for wider and more long term benefits to the 'target-group' has been lost. The level of investment has been retained through a process of redefining the objectives. But the donors can satisfy erstwhile liberal consciences and radical lobbies with PEP, which concentrates on the 'progressive' parts of the earlier search: more broadly conceived employment generation ideas (i.e. not just earthworks), innovation with NGOs and groups of people 'mobilised' by the government's Rural Poor Programme (RPP) in the Bangladesh Rural Development Board; credit support and technical advice networks. There are strengths and weaknesses with these strategies, but this is not the occasion to discuss them. The point, here, is that PEP represents approximately 10 per cent of the new programme funding.

If we now ask whether any other outcome was possible, we first have to recognise the fact that it is utopian to expect either enlightened donors or individual Bangladeshi officials and engineers to bear the responsibility for delivering the intended rights to employment (not just the work itself, but also conditions and wage rates) and new assets to the poor. We have seen that where a programme is to be implemented through existing governmental structures which uses locally selected Project Committees, this effectively precludes any enhancement of workers' rights. In these circumstances, compliance with the externally set goals can only be enforced through the efforts of the workers themselves. This means that success actually requires the mobilisation of claimants who bear all the risks of militancy in seeking fair wages, etc. since they also have to maintain their relationship with employers through whom they have to survive at other times of the year. Thus the burden of establishing these rights (and thus of ensuring that the programme's objectives are met) has been shifted onto those with the least power and the most to lose.
This problem can only be modified within the context of a centrally administered scheme where there are actual innovations in the mode of construction itself. In the existing schemes, for example, the emphasis on one-off, single season projects produced a lack of continuity in employment opportunities across successive seasons which was particularly disadvantageous for women, who were not so free culturally to travel to schemes in other localities to work in an area of strange men. It is difficult to mobilise and risky to be mobilised on such a short term basis. Employment practices therefore tend to change only when a new technological activity has been introduced, such as pipe-casting for culverts, or where the traditional structure has been completed (e.g. an embankment or an embanked road) and longterm maintenance is required.

This, therefore, suggests that any serious attempt to alter an existing system of distribution through an economic programme must look very closely not only at the administrative and political structures likely to be involved, but at the implications of the choice of technologies available to achieve the given physical objective. In the case examined here this was not done because a whole series of invalid assumptions were made about the political, economic and social context within which they were operating.

\section{Conclusions: The Alternatives}

Using a public sector strategy (i.e. LGEB, Upazila Planning Committees, engineering officials and nominated Project Committees), controlled by social forces opposed to the genuine advancement of the 'target groups' identified by the donors, was therefore an inappropriate means of achieving their objectives. This option clearly presupposes the existence of a regime sympathetic to these goals, and a state apparatus organised in such a way as to be able to deliver the services involved, something which manifestly did not exist in Bangladesh or in many other similar countries. Simply attempting to retrain and reorient the perspectives of officials, to give more authority to those responsible for ensuring that the social as opposed to the technical objectives will be met, will not resolve the problem of goal displacement in such a hostile environ ment. To increase the number of outsiders with supervisory/monitoring roles would only create more political and institutional tensions, and reduce the proportion of income spent on the poor, given the immense expense of maintaining expatriate technicians in the field. Hence it is clear that the problem of administrative reform in such contexts requires the ability to use more appropriate agencies to perform the functions required.

\section{Privatisation}

The most obvious alternative to the public sector 
would have been to use local private contractors more extensively in earthworks schemes, in addition to their use in pucca schemes such as bridge and culvert construction. In principle, the earthwork schemes would be put out to tender and adequate supervision established to ensure that technical standards were maintained. In this way many of the overheads and leakages, which have occurred in the actual project, might have been avoided. Would it be possible under such arrangements for more embankments, roads, and canals to be constructed with a much larger share of total expenditure being paid out as wages?

This option, of course, presupposes that local contractors with requisite skills and capital could be found, and that the donors could organise an effective tendering system to enforce minimum cost standards without a dangerous loss of quality. It is by no means certain that this could have been done in this part of Bangladesh, since few firms existed with the requisite technical capacity and all of them were directly tied into the political patronage networks. The end result might have been expensive and incompetent work given to the local contractor willing to pay the largest bribe to the local authority with the task of administering the local tendering system. The experience with local contractors on pucca schemes confirms this, certainly with respect to quality control where constructions have collapsed after cheating on estimates for materials. The opportunities to 'fund' local political alliances and patronage networks do not disappear with this option.

Thus the privatisation option presupposes the possibility of establishing an effective local agency capable of ensuring that the private agencies meet minimum standards, and this cannot simply be taken for granted. It is only the problems with the public sector strategy which compel the exploration of such private sector options. But transforming the state's involvement from a management to a regulatory role does not overcome all the problems of administrative interest and competence noted above.

This also presupposes, of course, that the state itself would have been willing to give up the patronage involved in public sector provision and to accept the alternative method. This, of course, raises questions about the degree of leverage available to the donors and the legitimate use of it. Given the heavy dependence on aid spending to sustain political support, one may assume that the regime would have been loth to reject a project out of hand because it was operating through the private sector, especially with the pressure from major donors like USAID and the World Bank in conjunction with commercial lobbies inside Bangladesh, to commercialise other sectors, such as agriculture. Under such conditions, small agencies like the Nordic donors only have leverage if they make common cause with the larger donors. The dilemma for Nordic donors is that they have been operating in an environment which, partly because of these pressures, has become increasingly hostile to the pursuit of responsible public sector management or regulation, while being concerned with the policy areas of equity and redistribution where private sector solutions will only institutionalise still further the power of local patronage networks over the poor. Privatisation would, in effect, involve surrendering the attempt to 'target' a specific stratum of workers (and thus to provide especially for women) or to enforce regulations as to trade union rights, conditions of work, and the payment of fair wages.

In the event, of course, the attempt to impose such conditions in an environment characterised by a large labour surplus and extreme social dependence was bound to fail, even when administered by a state agency supposedly directly responsible to the donor through the government. Further, the cost of attempting to monitor these conditions only reduced the level of employment - the cost of keeping one expatriate in the field would have been sufficient to add many dozen local workers to the payroll at the going wage rate. A substantial increase in the demand for labour for public works in itself could have been expected to push up the local wage rate and thus benefit not just the workers actually incorporated in the scheme, so that the negative consequences of the loss of direct control could be offset, to some extent, by the benefits incurred through the increase in overall employment.

\section{Local Non-Governmental Organisations}

Given the concern with redistribution and 'empowering' the poor, a more promising alternative has involved the attempt to provide resources to local NGOs supporting the groups which the programme wishes to help. In the last decade, a large number of indigenous NGOs have been set up working with the rural poor in consciousness-raising and incomegenerating programmes. Organised through institutions like BRAC and PROSHIKA, local groups have been involved in self-contracting with irrigation schemes and have been able to meet necessary technical standards, to meet their credit obligations on time, pay salaries to group members working on the schemes, and make net profits [see Wood 1984, and Wood, Palmer-Jones and Ahmed, forthcoming]. Since 1984, the IRWP and now RESP have worked through NGOs not just on the issue of claiming employment rights, but also on the creation of selfcontracting labour gangs, as an alternative to Project Committees and private contractors.

Thus, while operating through the existing private contracting network can only serve to reinforce the existing power structure, using such groups can serve to develop higher degrees of competence among the 
poor and dispossessed. Here, resources go direct to the 'target group' and leakages are minimised. The problems involved in using this method then arise out of the scale and spread of the groups actually in existence. It is easier to envisage poor groups, supported by NGOs, being more capable of sinking and managing local tube wells than building large and technically complex earthworks in a difficult physical environment. This probably means that the NGO option (the credentials and competence of such NGOs also have to be carefully monitored, since they, too, can be used as fronts by the rich and powerful) must be confined initially to relatively simple and small scale projects. It also suggests that considerable efforts should be put into finding effective means of getting resources to them and providing them with the organisational and technical competence required to ensure that they can do the job without damaging their autonomy.

In this process, these organisations contribute not just to the technical but also to the political competence of the poor. With resources behind them, they will begin to be able to challenge the political monopoly of the existing patrons, and be in a position to exercise more effective surveillance over the performance of the public sector agencies as well. At present, as we have seen, the inefficiency and corruption of the political and administrative elite is a function of their monopoly of information and control over all of the developed networks in the society. Only by enabling alternative sources of social organisation to develop (to create an effectively articulated 'civil society') can this control be challenged and a genuinely responsible administration created. Paradoxically, therefore, we can see that it is only by creating effective autonomous structures outside the state that the autonomy and honesty of the state itself can be guaranteed. However, a strong note of caution is required. NGOs should in no sense be regarded as a panacea for this process. There are contradictions, in which NGOs can become incorporated as mere delivery arms of the 'soft' parts of government and donor programmes. As their own support services to the poor expand and become more complex, so their organisations may become more managerial and routine in style, and less inspirational. The political competence of the poor as a source of accountability for state practice will only arise through the long haul of poor groups creating wider federations and unions to represent their interests as an organised class.

\section{References}

Wood, G. D., 1983, Landless Participation and Mobilisation in the Intensive Rural Works Programme, SIDA, Dhaka

-1984, 'Provision of Irrigation Services by the Landless An Approach to Agrarian Reform in Bangladesh' Agricultural Administration 17, pp 55-80

-1985a, 'Editorial' in G. D. Wood (ed.), Labelling in Development Policy, Sage, London, for ISS, The Hague

- 1985b, 'Targets Strike Back - Rural Works Clainiants in Bangladesh, in G. D. Wood (ed.) op cit., pp 109-31

-1986, 'Don't Give Them My Telephone Number Applicants and Clients: Limits to Public Responsibility' Public Administration and Development vol 6 no 4

Wood, G. D., Palmer-Jones, R. and Ahmed, Q. F., (eds.), Social Entrepreneurialism. - Water Selling by the Landless in Bangladesh (forthcoming) 